\title{
"MAKING WINDOWS WHERE THERE WERE ONCE WALLS": TRANSFORMATION IN HIGHER EDUCATION CURRICULA
}

\section{K. Menon*}

Academic Planning and Academic Staff Development

e-mail: kirtim@uj.ac.za

\section{G. Castrillon*}

Academic Planning and Quality Promotion

e-mail: gloriac@uj.ac.za

*University of Johannesburg

Johannesburg, South Africa

\section{ABSTRACT}

As the events across South African campuses in 2015 and 2016 have shown, if there are any meaningful insights into quality and transformation, lessons could be learned from conceptions of madness. The intention is to examine curriculum transformation in South Africa and whether there are lessons to be drawn from other post-colonial environments' experiences. In order to interrogate curriculum transformation, a shared understanding of the purpose of higher education especially in relation to its transformative potential and value needs to be established. As part of this exploration, how the curriculum has become a key focus area in the pursuit of a transformation agenda will be discussed. Given the perceived centrality of the curriculum, the role of the state in setting and supporting the transformation agenda is examined, as are the components of the system that either drives or inhibits the achievement of effective curriculum transformation.

Keywords: transformation; curriculum; South African higher education; quality

"People know what they do; frequently they know why they do what they do; but what they don't know is what what they do does." Madness and Civilization: A History of Insanity in the Age of Reason by Michel Foucault (1988).

\section{INTRODUCTION}

In Madness and Civilization, Foucault argues that madness is not a naturally occurring constant, but a changing social construct that depends on the society in which it is defined. In much the same way, it is argued in this article that conceptions of quality and transformation in higher education, like madness, rely on a variety of institutional, cultural, and intellectual structures that determine how we "know" and "experience" quality and transformation. We are, according to Foucault, "all involved in creating the structures that constrain us" and remain "central to 
this construction" (Spracklen 2011, 170), whether in metal music (the subject of Spracklen's article), or in higher education, (the subject of this article).

As the events across South African campuses in 2015 and 2016 have shown, if there are any meaningful insights into quality and transformation, lessons could be learned from Foucault's conceptions of madness, as much as from other postmodern conceptions of meaning. The postmodern environment is about multiplicity and is "a time of much change and confusion" (Stone 1994, 50). Characterised as it is by "ambiguity, tentativeness, and [a] focus on the present and the particular", it is not easy to pose questions that avoid the risk of either reducing or reifying "that which is complicated" (Stone 1994, 50). The aim in this article is to begin, perhaps, to construct a genealogy of transformation in higher education in South Africa and to consider curriculum transformation and explore whether there are lessons to be drawn from other post-colonial environments' experiences.

In order to interrogate curriculum transformation, a shared understanding of the purpose of higher education especially in relation to its transformative potential and value would be useful. This article will demonstrate however that although the curriculum has become a key focus area in the pursuit of a transformation agenda, there has been little interrogation or enquiry into the meanings of transformation and how it manifests in the very curricula at the core of the enquiry. The role of the state in setting and supporting the transformation agenda is examined, as are the components of the system that either drives or inhibits the achievement of effective curriculum transformation. The value of this article for higher education lies in the provision of a retrospective about how "notions" of curriculum transformation and the architecture put in place by regulatory bodies and policy makers to give effect, may very well have served to inhibit rather than facilitate the envisaged change.

\section{THE PURPOSE OF HIGHER EDUCATION}

It is common cause that higher education (HE) serves a variety of social purposes, among which is the obligation to contribute "to the social ... cultural and intellectual life of a rapidly changing society", to socialise "enlightened, responsible and constructively critical citizens" and to "help lay the foundations of a critical civil society, with a culture of public debate and tolerance", as described in the White Paper (DoE 1997a, 1.12, 1.3, 1.4). According to the White Paper, the purposes of HE are crucial social purposes. Among these is the need to:

- mobilise "human talent and potential through lifelong learning",

- "provide the labour market [...] with the ever-changing high-level competencies and expertise necessary for the growth and prosperity of a modern economy", 
- undertake the "production, acquisition and application of new knowledge",

- "contribute to the creation, sharing and evaluation of knowledge,"

- "address the development needs of society" and "the problems and challenges of the broader African context,"

- contribute "to the social ... cultural and intellectual life of a rapidly changing society",

- $\quad$ socialise "enlightened, responsible and constructively critical citizens", and

- "help lay the foundations of a critical civil society, with a culture of public debate and tolerance".

A final goal, and one key to this article, is the expressed need to "improve the quality of teaching and learning throughout the system and, in particular to ensure that curricula are responsive to the national and regional context" [emphasis added]. The achievement of this last goal, which is inextricably linked to the promotion of quality and quality assurance through the accreditation of programmes, programme evaluations and institutional audits (DoE 1997a), falls squarely into the ambit and mandate of the Council on Higher Education (CHE) and the South African Qualifications Authority (SAQA) as well as any other body that may be relevant such as a professional body.

The aims of HE as expressed in the White Paper are not however uncontroversial. As Salim Badat (2010) argues, "[a]n instrumental approach to higher education which reduces its value to its efficacy for economic growth, and calls that higher education should prioritize professional, vocational and career-focused qualifications and programmes and emphasise 'skills' development is to denude it of its considerably wider social value and functions". It is worth bearing in mind the question of whether transformation priorities in respect of the curriculum have been eclipsed by more utilitarian, instrumentalist conceptions of education (Le Grange 2016). As Le Grange points out, many conceptions of curriculum are embedded in a factory model of education, requiring that objectives be met and, in more recent incarnations, that outcomes be achieved (Le Grange 2016, 7). The current regulatory framework has focused almost exclusively on what has been termed the "explicit" curriculum. The explicit curriculum includes items such as module outlines, prescribed readings, assessment frameworks, programme purpose statements, and so on. In the current regulatory framework, it is the "hidden" curriculum ("what students learn about the dominant culture of a university") and the "null" curriculum ("what universities leave out") that are core to transformation, but on which there has been little focus (Le Grange 2016, 7). 


\section{WHY CURRICULUM TRANSFORMATION SPECIFICALLY?}

The first way in which the curriculum has been placed on the transformation agenda is expressed in the White Paper 1997 (DoE 1997a), which speaks to more broad imperatives than economic transformation. The second, is the focus on education that prioritises professional, vocational and career-focused qualifications in ways that may have served to undermine the first (Badat 2010, 16). The Ministerial Report on Transformation (2008) identified curriculum as a key lever for change, with an assessment required of how effectively the "stage" has been set for the achievement of this goal. Although the intention of the Ministerial Committee was not to delve deeply into curriculum matters, it nonetheless included this in its 40 recommendations, again placing curriculum transformation at the centre. The 2010 Higher Education Summit reached the conclusion that what emerged with regards to curriculum transformation was that curricula need to be aligned to the expectations of students and their lived experiences, and that consideration be given to extending the undergraduate degree from three years to four years. Let us assume that these statements are meant to serve as clear "triggers" to transformation, and in particular to curriculum transformation, it is still not clear how the achievement, or the assessment of the degree of achievement, will take place. That the curriculum remains at the centre, and that the achievement and measurement of transformation are crucial, was reiterated in the 2015 Summit. Yet, if we are to gauge by the widespread events in the sector in 2015 and 2016, it is clear that higher education institutions may not yet have moved sufficiently, or sufficiently in the right direction. As Brian Kamanzi notes, "[t]he curriculum through the ages, as but one dimension, should therefore not be seen as 'innocent' nor taken for granted but [as the] the site of contestation in precisely the same way as the society that gives it meaning" (Kamanzi 2016). The apparent failure to address the transformation requirements in the sector must give pause to academics and university administrators. It ought also to lead us to question the policy framework that provides the paradigm against which such measures are devised, implemented, and measured. As Barnett, Parry and Coate (2001) argues, the principle of performativity is vested in the regulators' approach to HE which relies for its value on the "relationship of Higher Education to the labour market" and, along with those aspects of curriculum that can be measured and quantified, appears to have become a core focus of the South African HE project. There is a dissonance between policy intent and the realities of transformation, or the lack thereof, in the institutions. Yusef Waghid and Nuraan Davids elaborate that "although higher education policies create the impression of inviting deliberative engagement and the cultivation of decolonised pedagogical knowledge spaces, the recent - and increasingly violent - spates of student protests suggest that this in fact might not be the case" (Waghid and Davids 2017, unnumbered). 
It is clear that we need to ascertain the government's role in actively steering the higher education sector. It is salient to refer to Osborne and Gaebler (1992) who state, "after all, those who steer the boat have far more power over its direction than those who row it" (Osborne and Gaebler 1992, 32). In broad terms, the policy framework which provides for the steering mechanisms of state (and which are clearly internationally present) to effect the transformation of the curriculum, are rendered useless if institutions do not give effect to these imperatives in the classrooms. In effect, the power inversely rests with academics or the individual universities especially in university teaching, where the responsibility is "in most cases devolved to the discretion of individual teachers to teach pretty much how and what they wanted to, the name of 'academic freedom"' (Biggs 2014, 9-10). As in our case the result is widely varying interpretations of what constitutes a curriculum, and even teaching and learning.

A number of "transformation" efforts and programmes emerged, prompted at least in part by the imperatives in the national policy documents. On the one hand, the transformation agenda was set by the state (DoE 2001) and a set of tools was devised (these include compliance with the requirement of the CHE and SAQA). On the other hand, the ideals of academic freedom and institutional autonomy remain at the core of all such policies or statements, including those expressed in the compliance requirements set by the Department of Higher Education (DHET), CHE and SAQA. So although the stated approach is that of valuing individual institutional academic freedom and autonomy, at the level of functional activity in HE even though targeting transformation, increasing regulation has focused on compliance in respect of the structure of qualifications and with the introduction of the term "learning programme" (Le Grange 2009), and has clearly been pulling higher education institutions (HEIs) in opposite directions. For the purposes of external regulation, a learning programme is considered. The responsibility for constituent parts which are modules vest across departments or schools, in some cases across faculties. The responsibility for the module is thus the responsibility of the academic. The development of learning programmes is linked to the inherited Western structures of organization in our universities (Le Grange 2009). Ramrathan (2016) asks in response to the regulatory environment especially in relation to qualifications and programmes, "Why are we, as South African intellects and policymakers, continuing in this instrumental and numerical mode of thinking and response?" (Ramrathan 2016, 1). The focus on the mechanical (or performative) aspects of the construction of a learning programme is firmly embedded in a significant array of documents, including the White Paper 1997, in the HEQC Founding Document (2001), in a variety of SAQA documents, in the Higher Education Act, Act 101 of 1997, the Norms and Standards for Educators (GN 20844, 2000), the HEQC: Programme Accreditation Framework (2002), the Higher Education Quality Committee's 
(HEQC's) Framework for Institutional Audits (2004), the Higher Education Qualifications Framework, the new Minimum Requirements for Teacher Education Qualifications (2015), and the National Reviews conducted by the HEQC of the LLB, MBA, M Ed, PGCE, B Ed and ACE programmes. It is essential to understand fully that, as opposed to enabling transformation of any curriculum, these documents and approaches have served fully and completely to focus institutions on compliance. Compliance has been driven by fundamentally technical concerns such as credits, notional hours, articulation possibilities (real or constructed), learning outcomes, NQF levels, level descriptors, module types and learning activities. What has happened is that "curriculum" has become an aggregation of assessments of the apparent complexity (NQF levels, module outcomes, etc.) and volume of learning and teaching (credits, weighting, teaching and learning activities, etc.). These initiatives, external to HEIs, have largely "become" the language of curriculum design and planning. However, the master they serve is compliance to the technical aspects indicated, and not curriculum, and certainly not curriculum in any transformative manner. Curriculum, defined in any way other than performative, is neither measured nor evaluated and there are no "metrics" in place that can be used.

The question is therefore whether the adoption of the language of regulation is a valid or effective barometer for measuring transformation of the curriculum. What remains unexamined is the actual, delivered curriculum that is embedded in the qualification and is presented "live" in the classroom and in the students' every interaction with the institution. The embedded curriculum is not moderated or evaluated, barring through possible peer review processes or external examination within institutions bearing in mind that the objectives of such processes are not directly related to transformation assessment. Reviewers are seldom asked to evaluate curriculum transformation nor is there a shared understanding of what this entails or implies for the object/subject under scrutiny. The custodians of curricula are in most instances, the individual academic or group of academics. This custodianship may be tempered by institutional typology, governance processes and practices, or even by moderation or other peerbased exercises, but nonetheless, it is nowhere interrogated by the regulatory provisions in the framework within which HE operates.

The framework's limitation in this regard has its roots in its broad historical purposes. Prior to the promulgation of the Higher Education Act (DoE 1997b) and its regulations and accompanying documents, national policy had addressed the public and private sectors very differently. The private sector was unregulated, and not much concerned with HE. The public sector was regulated to the extent that the curricula for technikon qualifications were determined nationally, and were set out in state documents to which the technikons had to 
adhere. ${ }^{1}$ The re-organisation of the public sector and the consequent mergers and distinctions between university "types" (Arnolds, Stofile and Lillah 2013) propelled universities, comprehensives and universities of technology to develop and own the learning programmes leading to their qualifications. The new regulatory framework, set out above, changed the landscape almost completely. All private HEIs are now regulated and required by law to comply, as are the universities. Access to the right to deliver HE is monitored by the gatekeeping function of the HEQC. The CHE Accreditation Framework and Accreditation Criteria (CHE 2004) one to nine are the minimum barriers to entry for any new learning programme or institution in the system. The criteria are set out in Table 1.

Table 1: Criteria for programme input: Areas and relevant aspects

\begin{tabular}{|c|c|c|}
\hline Areas & Relevant aspects & Criterion \\
\hline 1. Programme design & $\begin{array}{l}\text { - Relation to institution's mission and planning } \\
\text { - Needs of students and other stakeholders } \\
\text { - Intellectual credibility } \\
\text { - Coherence } \\
\text { - Articulation } \\
\text { - Characteristics and needs of professional and } \\
\text { vocational education } \\
\text { - Learning materials development }\end{array}$ & Criterion 1 \\
\hline $\begin{array}{l}\text { 2. Student recruitment, } \\
\text { admission and selection }\end{array}$ & $\begin{array}{l}\text { - Recruitment } \\
\text { - } \text { Legislative issues } \\
\text { - } \text { Widening of access } \\
\text { - } \text { Equity } \\
\text { - } \text { Assumptions of learning } \\
\text { - } \text { Professional needs } \\
\text { Capacity of the programme to offer quality education }\end{array}$ & Criterion 2 \\
\hline 3. Staffing & $\begin{array}{l}\text { - } \text { Qualifications } \\
\text { - } \text { Teaching experience } \\
\text { - } \text { Assessment competence } \\
\text { - } \text { Research profile } \\
\text { - Sizf development } \\
\text { - } \text { Full-time and part-time staff } \\
\text { - } \text { Legislation and conditions of service } \\
\text { - Procedures for selection, appointment, induction and } \\
\text { - } \text { payment } \\
\text { - } \text { Administrative and technical staff }\end{array}$ & $\begin{array}{l}\text { Criterion } 3 \\
\text { Criterion } 4\end{array}$ \\
\hline $\begin{array}{l}\text { 4. Teaching and learning } \\
\text { strategy }\end{array}$ & $\begin{array}{l}\text { - Importance of promotion of student learning } \\
\text { - Institutional type, mode(s) of delivery and student } \\
\text { composition } \\
\text { - Appropriate teaching and learning methods } \\
\text { - Upgrading of teaching methods } \\
\text { - Targets, implementation plans, and ways to monitor, } \\
\text { evaluate impact, and effect improvement }\end{array}$ & Criterion 5 \\
\hline $\begin{array}{l}\text { 5. Student assessment } \\
\text { policies and procedures }\end{array}$ & $\begin{array}{l}\text { - Internal assessment } \\
\text { - Internal and external moderation procedures } \\
\text { - } \text { Monitoring of student progress } \\
\text { - } \text { Validity and reliability of assessment } \\
\text { - Recording of results } \\
\text { - } \quad \text { Recurity } \\
\end{array}$ & Criterion 6 \\
\hline $\begin{array}{l}\text { 6. Infrastructure and library } \\
\text { resources }\end{array}$ & $\begin{array}{l}\text { - Venues } \\
\text { - IT infrastructure and training } \\
\text { - Size and scope of library resources } \\
\text { - Integration of library resources into curriculum }\end{array}$ & Criterion 7 \\
\hline
\end{tabular}




\begin{tabular}{|l|l|l|}
\hline Areas & Relevant aspects & Criterion \\
\hline & - Management and maintenance of library resources & \\
\hline 7. Programme administrative & - Library support and access to students & \\
services & - Provision of information & Criterion 8 \\
& - Dentifying non-active and at-risk students & \\
\hline 8. Postgraduate & - Ensuring the integrity of certification & \\
& - Policies, regulations and procedures & Criterion 9 \\
& - Equity and access and procedures & \\
\hline
\end{tabular}

Universities and private providers alike are to obtain PQM or registration approval from the DHET, as well as accreditation from the HEQC which means meeting the minimum for each of the criteria above (a total of approximately 70 areas of compliance), and registration of the qualification from SAQA. However, critically, none of the above requirements refers overtly to curriculum, nor to transformation. The closest one comes to curriculum transformation in the $\mathrm{CHE}$ accreditation criteria is in "programme review". However, again, the issue of curriculum here is limited to its meeting "national requirements" (Criterion 1) and "academic coherence and integrity" (Criterion 10).

Although the purpose of the CHE Accreditation Framework is, broadly, the assurance of quality in HE, it remains the means through which entry into HE is regulated, whether of new providers, or of new and existing qualifications, and the assurance of the quality of curriculum transformation remains embedded in the governance structures of each HEI with little to guide either the "what" or "how" of curriculum transformation in place. In the public sector, Senate performs the high-level function of ensuring that the outcomes of a qualification meet the requirements of the institution and, possibly, of the framework. At public universities, this function is ordinarily devolved from Senate to Faculty, and from there to Schools or Departments with accountability chains inserted by Senate which has the final authority to approve developed programmes. The extent to which a senate or equivalent structure has clear, defined mandates to effect curriculum transformation at the point when approvals are required, is dependent on institutional arrangements. Here is the crux: in every institution, and regardless of what a senate has decided, it is the individual academic or academics who deliver the programme (at the level of the module) to the student and whose delivery encapsulates (or otherwise) the transformed (or otherwise) curriculum. The absence of monitoring or evaluating curriculum and curriculum transformation is the gap in the system. The learning programme, its outcomes, its intention, its assessment, its evaluation - whichever aspect is chosen - remains separate from any high-level commitment to the degree or meaning of transformation. In this way, transformation in the curriculum at all institutions continues, functionally, to escape scrutiny until, for example, student protests erupt. Institutional self-reflection on the extent and 
degree of the transformation of the curriculum remains at the discretion of the management structures at a variety of levels in the university.

Of course, some will counter that there are other mechanisms in place through which institutions assure themselves of transformation, other than the high-level activities outlined above. For example, there is internal and external moderation in which academics assess whether the individual academic or academic department has achieved the stated aims of the module or subject in question. There are limitations to this system too, and the system's key flaw is that it has the potential to remain self-referential. For example, the selection and appointment of moderators, a peer review system in itself, is an institutional prerogative that is not ordinarily driven by transformation imperatives, but is driven by a range of considerations including professional courtesy, inter-institutional engagements and, in some instances, simply by the compliance requirement set by the HEQC. Furthermore, moderation is only required in the modules at the exit level of qualification. In a three-year qualification, this means that potentially a full two years are taught with no interrogation of transformation. Finally, it is usually not within the mandate of external examiners to comment on transformation of the curriculum given that the focus is usually on measuring whether the outcomes of a stated module are met by the assessment, and whether the marking process has been fair and objective. And, even if it were within their mandate, it is not clear against what yardstick they would measure this, nor even how competent they would be to do so.

A second mechanism that could be said to address transformation comprises the quality assurance internal reviews to which every institution is bound. Most institutions run these every three to five years; however, they tend to have one aspect in common: they are internally run, with external representatives from industry and academe, and tend to focus on the input (programme of learning, assessment, teaching, and so an) and the output (number of graduates, employability, programme impact, etc.) factors in a programme. It is not clear how many, if any, of these kinds of reviews are engaging with the question of the transformation of the curriculum. As with moderation, the absence of a shared understanding of transformation of the curriculum means that it is not clear what they would measure, even if this were to be a requirement.

The third mechanism is National Review, undertaken by the CHE. The reviews take place in terms of a set group of criteria relating to the kind of programme offered, overlaid on the standard accreditation criteria, or at least incorporating these. The individual findings are sent to the institutions, and an aggregated national report on the qualification and its offering is released. The teacher education review, by way of example, assessed programmes in this area to the level of modules and courses. It interrogated the extent to which the regulatory 
requirements for teacher education had been met, and the programme design to the extent that it complied with the requirements of the Higher Education Qualification Sub-Framework and the CHE criteria. National reviews provide a perfect opportunity for the interrogation of the achievement of the transformation directive. However, and this is a key consideration, it is again a peer-reviewed process and consequently may be inherently limited by the values, views and attitudes towards notions of transformation of those who moderate. Peer review therefore remains arbitrary, and is consequently problematic. The biases and institutional and personal agendas of panel members mean that the results of these reviews are found to be less than satisfactory, and a meaningful opportunity for the interrogation of what is meant by transforming the curriculum and whether and how it has or is able to be achieved is lost. However, the CHE Framework for National Standards is silent on transformation and has other roles assigned to the purpose of standards (CHE 2013). In some cases, the role of the professional boards in review, approval, endorsement or accreditation, creates competing tensions with compliance to professional standards eclipsing transformation imperatives.

Thus, the extent to which has there been curriculum transformation at the fundamental level of discipline, and in the modules that comprise a learning programme, is difficult to ascertain except at the level of the faculty or even the department, school or unit. Although the national reviews are critical and serve some key purposes related to a curriculum (for example, relating to credit accumulation transfer, or equivalence across the sector), the results do appear to confirm the view that external agencies cannot be responsible for, nor potentially even assess, the effective transformation of a curriculum.

In effect, the somewhat heavy-handed focus on compliance in the higher education sector may very well have prompted what Jean-Francois Lyotard (1993) has referred to as "performativity", which has resulted in institutions providing templated responses to identified external and internal reviews (and this is true also of institutional submissions to the CHE and SAQA). There are approximately 42 minimum standards applicable to programme accreditation in the external reviews. Only three to four of these focus explicitly on the curriculum. It is not clear therefore whether the task of the external agency is in fact to focus on curriculum transformation, or whether this task is being conflated and consequently subordinated to other accreditation activities. It would appear to be the latter. Add to this the fact that attempts to influence university curricula are often seen as limitations on the principles of autonomy and academic freedom, and further complications arise. Cross underlines the problematic of oversight in the area of curriculum transformation; he attests: "there has been no systematic attempt to develop a campus wide approach to curriculum transformation or diversity related research" (Cross 2004, 397). This view is a commonly held one, and one with 
which Jansen (1998) concurs. He argues that a narrow focus on indices "signals little of the depth, quality and sustainability of transformation given the fixation of this approach with numerical indices of performance such as the 'number of African students enrolled' without inquiring, for example, about the nature of the curriculum experience" (Jansen 1998, 106). Thus, while curriculum transformation remains an apparently significant goal to which all institutions are to aspire, there appears to be no systemic response able to capture and assess whether and to what effect it is occurring.

There was clearly an expectation, evident in the national policy documentation, that higher education would "engage" and "transform" in line with the policy, and the need to do so was stated. However, it is not clear what transformation would or should look like, and how we would know when it has taken place, or how effective it has been. We have been left in a situation where there are no transformation "windows" in the "walls" that the compliance framework has built. If curriculum transformation is to be achieved, it is clear that an overhaul of the current regulatory frameworks is required, to ensure that these serve as triggers for curriculum transformation as opposed to creating barriers which subvert change initiatives. The reference to Foucault at the start of the article, to people knowing what they do and why they do it, links clearly to the development of the policy and accreditation frameworks and activities to effect transformation. However, it is clear that for the most part we are still not clear what this has given effect to in terms of transformation. Indeed, there is no consensus on what is meant by curriculum transformation. For example, it has been taken to mean the inclusion of the work of African scholars, the development of new pedagogical approaches to teaching and learning, the act of teaching in African languages, or of providing relevant terminology for specific subjects in African languages (Garuba 2015; Shay 2016). There is no shared understanding of what is meant by the need to transform the curriculum, or to decolonise the curriculum, nor is it clear where this responsibility lies. It is evident from recent events that at least some of these unaddressed questions have been central to the student (and staff) protest activities on South African campuses for the past few years.

The Ministerial Report on Transformation (RSA 2008) identifies curriculum reform as a key element of transformation, and the 2010 Higher Education Summit concludes, "Curricula need to be aligned to the expectations of students and their lived experiences" (RSA 2008). It is not clear however why and how aligning a curriculum to students' expectations would constitute transformation. The assumption that there is an inherent logic in this is problematic. The 2015 summit statement asserts that "Research and dialogue on curriculum transformation must be supported, and resources allocated to enable re-curriculation and curriculum development processes. There should be an increasing focus on curriculum development 
initiatives, which examine new and alternative contents and pedagogies which are relevant to the South African context" (RSA 2015). However, although these are all clearly triggers for "transformation", and clear directions to the HE sector to respond, they neither map the path nor define the destination in certain terms. Nor is it clear that the state has prioritised these goals as part of its resource allocation to public providers.

What has happened to the curriculum in the 21 st century in the context of the monitoring framework is what Achille Mbembe (2015) calls "the quantified subject". In this model, students are viewed as consumers and customers, and the curriculum needs to align to the economic imperatives of the country. Most institutions grapple with the intractable tension between making curricula relevant for a specific employment sector and holding true to a discipline. At the same time, the pressure on universities to continue to produce "blue-sky" research continues unabated, and the need to perform internationally is continuously emphasised. The contradictions between this push for research productivity and the key questions asked of institutions are revealing of the fissures in the system. When universities are required to focus on how to make students employable, and on how to ensure that curricula are aligned to sector, market and employer needs, then curricula may be broken into a myriad of units in which the whole is not necessarily greater than the sum of its parts. In fact, in some highly occupation-related professions, curricula have been dissected down to the level of activities and skills. Allais has argued that the neutrality of the approach to unit standards disguises choices made in curricula in that "they ostensibly define 'outcomes', which can be attained through a range of different learning contexts, and curricula, and they are set up as neutral vehicles against which different ideological approaches to curriculum can be implemented" (Allais 2003).

In the recent furore triggered by the Rhodes must Fall Campaign, the spotlight has been placed firmly on the extent to which curricula at universities have been transformed. The decolonisation project is, however, not easy to grasp in the absence of a map. What does the decolonised curriculum look like and how do we get from where we are to that destination? Furthermore, it is clear that at the heart of curriculum issues is the fact that "curriculum communicates what we choose to remember about our past, what we believe about the present, what we hope for the future" (Pinar 2004, 20). Curriculum debates are thus so often also debates about "national identity" (Pinar 2004, 20). Ndlovu-Gatsheni (2013) argues that a colossal task is to explore "epistemological issues, politics of knowledge generation as well as questions of who generates which knowledge, and for what purpose" (Ndlovu-Gatsheni 2013, 11). The decolonial project, in its postmodern approach to realities in higher education (as elsewhere), demands that we engage as much with the framework within which change is negotiated and 
effected, as we do with the theoretical and paradigmatic underpinnings thereof. The question is whether curriculum transformation is constrained by the architecture of higher education. Is it within any university's ability to trigger the transformation of the curriculum given that the individual academic and structural units within the institution remain in control of the curriculum and exert direct authority in the delivery of the curriculum? The constant need to monitor the implementation of even administrative policy would appear to indicate that an even larger disjuncture is possible between national policy, university policy and the smaller individual units and persons who deliver on the policy commitments made. Can a senate or equivalent body actually exercise the kind and extent of oversight implicit in this approach, and if it can, what measures and criteria will it have access to in order to determine what decolonisation is and whether and how it has been effected? Additionally, as there is more and not less pressure on universities to achieve and retain competitive spots on the global university rankings, it leads some to question whether global relevance and transformation are mutually exclusive. For example, Crowe (2016) stated that "decolonisation is inherently locally socioeconomico-politically selective, potentially exclusionary and deconstructive, and requires ideological expurgation and nonepistemic-based staffing attrition before there can be reconstruction" (Crowe 2016). The myopic view is self-referential in the extreme with assumptions being made regarding the dominance of Western knowledges and a dismissal of epistemic pluralities that could arguably strengthen curriculum in fair and equitable ways. Academic knowledge "including what is taught, by whom, to whom, and for what purpose remains an important site of political contestation" (Kamola 2011, 163).

Concepts of academic freedom and institutional autonomy wrestle with qualification structures and learning programmes as defined (DoE 1997a). As a result, the focus of quality assurance engagements in South Africa has continued to be with general compliance to a list of requirements relating to the technical considerations of credits, learning outcomes, NQF levels and the ostensible complexity and volume of learning as linked to the various levels and qualification types. These initiatives remain external to the HEI, and the delivered curriculum remains in the domain and control of the individual institution, or individual academic. Between 1994 and 2000, "transformation" of the curriculum was taken to mean compliance with the requirements set by SAQA. It is not clear, however, that this was either the purpose or outcome of this process, or even whether SAQA as a body was able to respond to such a need. The artificial construct through which transformation of the curriculum was meant to be achieved was so templated, and arguably so superficial, that it is not possible to assert that it has had any impact at all on many of the structural aspects of education so desperately in need of amendment. The key question remains therefore whether an apex body such as SAQA (then) 
or the CHE (now), which defines the parameters of quality and which then judges compliance with these parameters, has any role in ensuring and assuring transformation of the curriculum across institutions. It is not clear how and whether the historically circumscribed epistemological assumptions about knowledge have been challenged at all as a result of the power implicit in the engagement with the quality assurance agencies. SAQA and CHE compliance activities have become (or indeed in many ways, always were) instances in which the HEI's role is to comply, and the SAQA or CHE's is to confirm compliance, often in most unsatisfactorily reductive ways (see below). It is clear that based on the current indicators, the kind of transformation that has been called for is most unlikely to be effected by the applications of the systems of monitoring and compliance managed by the current agencies.

To some extent, and almost 20 years later, the exercise in quality assurance and the transformation of the sector remains fundamentally reductionist. The focus on the explicitness of outcomes, on module constituents (such as credits, outcomes, specific assessment criteria) and on learning programmes (with much the same focus) has missed a key aspect of transformation: that of input. Even using a fairly standard business model of input, process and output, the South African system has since 1994 been almost entirely focused on output with measures of success being quantitative indicators like graduates, enrolments etc. If the transformation of the curriculum is to be an object of analysis, the current system will need to be recalibrated so that adequate attention is paid to the issue that will enable universities to delve more deeply into curriculum issues, while removing the over-reliance on the technical issues that currently strain the entire system. The reaction to the overtly technical aspects of qualifications has been to breed an army of employees and consultants well-versed in the demands of the templates and sufficiently literate in their requirements to satisfy the quality bodies without having to effect any substantive changes to the curricula of the qualifications offered. Never in the South African system has there been any tool, paradigm or mechanism through which HEIs have been able to measure the transformation of the curriculum at the level of the discipline or at the level of the modules comprising the learning programme. Nor has this ever been requested of them. The fact is that external agencies cannot be responsible for the transformation of the curriculum, and "templated" responses such as those in circulation currently serve to ensure that the quality assurance agency is satisfied even as the institution or individual academic may be warding off (or entirely ignorant of) attempts to influence curricula. Such actions are clearly in line with the principles of autonomy and academic freedom. However, even a superficial survey of South African qualifications shows that almost all qualifications are benchmarked against those of western universities, a benchmark that SAQA's “international comparability" requirement entrenches in favour of local, regional or 
continental transformation agendas, and notwithstanding the transformation policy statements which demand ever more complex responses than international equivalence, however that may be defined.

Given that we have no consensus and no clarity in our understanding of what is meant by curriculum transformation, and that in effect this has not been a focus of the quality assurance exercise even in the context of national policy, it ought to have come as no surprise that students are baying for change. It is, quite simply, unclear to academics and students what transformation means, what it requires, and what it implies for the approaches to teaching and learning adopted in our institutions. Furthermore, it is not clear how these questions are meant to be addressed in the absence of a shared understanding of what decolonising the curriculum would entail. Where does the responsibility for the development of a shared understanding of transformation of the curriculum lie? A variety of responses to what it means to be transformed have arisen. As indicated above, the locus of transformation remains a challenge to its definition. The $\mathrm{CHE}$ is mandated to provide advice to the Minister on all aspects of HE policy, to develop and implement a system of quality assurance, to monitor and report on the state of the higher education system which, importantly, includes assessing performance of the higher education system against goals, and to contribute to the development of higher education (CHE 1998). However, the distance between the $\mathrm{CHE}$ and its mandate to drive and report on the achievement of transformation, and the universities and private providers responsible for its implementation is further complicated by the realities of a hugely differentiated HE system. The trajectory from triggering transformation to its consequent achievement is not linear, and depends on a multitude of academic and intellectual contexts, multiple interpretations of discourse, and deeply contested and complicated actions.

It is a truism that a university collects and produces knowledge, and that this is one of its core functions. However, it is also true that the university is equally responsible for the dissemination and reproduction of knowledge. The manner in which the latter is undertaken is commonly referred to in South African as the teaching and learning strategy, and is the focus of several of the quality assurance criteria (notably Criterion 1 and 5). In these criteria, the teaching and learning strategy as expressed is about how the outcomes are "aligned" to the level descriptors, so that assessment may accurately measure their achievement in keeping with the mode of delivery of the programme. Nowhere in any of the criteria is the manner or values underpinning delivery interrogated. It is not clear at all how the departments or HEIs are to assess this, or address it if weaknesses are found. Student-academic interactions remain the preserve of the institution to the largest extent.

Although there has been a measure of success in curriculum transformation in relation to 
making qualifications relevant for the economy or the market place, this has been largely as a result of ensuring graduate employability, as defined by sectors, and as required by the professionalisation of curricula in response to professional body requirements. In this process, the focus has been on the inclusion of practical application, skills and applied competences. In the flurry of curriculum reforms, and judging by the presentations made at the HE Summit, transformation has been viewed primarily as what may be counted and measured, and employability, or the satisfaction of professional sector needs fits more readily into this category. However, it is true, In William Bruce Cameron's words, that "not everything that can be counted counts, and not everything that counts can be counted" (Cameron 1963, 13). The lack of shared understanding of what is meant by transformation, and a lacuna in the mechanisms continue to complicate the entire transformation enterprise.

Clearly, such concerns are not limited to South Africa, and similar considerations prevail in the Botswana system. Despite significant engagements in Botswana on the part of the state, Pandey and Moorad (2003) note that "not much reflection or research has been done on the nature of the curriculum and how it relates to the whole process of change". The transformation of the Botswana system focused on all levels of education, from junior school to university, and there was no limitation on funding with the state able to fund its entire programme. Nonetheless, the process of transformation has not been as effective as envisaged. Pandey and Moorad (2003) note that reasons for the lack of success are both educational and sociological, and that active resistance in some areas was also identified. The authors argue that despite the best policy intentions of the state and of the varied participants, the nature and structure of the Botswana educational system has not escaped the colonial past and consequentially, repeats hierarchies of class. The transformation agenda has not resulted in the "radical change or social transformation required to realize the educational goals and national visions" (Pandey and Moorad 2003, 171).

Similarly in Brazil, Lopes and De Macedo (2003) examined the transformation exercises undertaken from the 1980s and focused on the 1990s. In their assessment, the approach adopted in Brazil was characterised by its multiplicity of approaches and activities, which included curriculum thinkers and writers, but also sociologists and philosophers. First, a "deeper sociological approach, as opposed to the hitherto dominant psychological thought" is evident. Curricula as a forum for power relations was a key element of the approach undertaken. A comprehensive literature on the political nature of the curriculum developed (Lopes and De Macedo 2003, 188). Secondly, the link established by Foucault between knowledge and power allowed for the questioning of knowledge as a source of "liberation, enlightenment, and autonomy". The "decentralized micropowers" (akin to the units of a learning programme such 
as outcomes and modules referred to above) were seen to be both coercive and productive (Lopes and De Macedo 2003, 192-193). The authors conclude that as a result of this history of engagement with the issues, the curriculum field in Brazil is undergoing a redefinition that involves a "cultural change" associating "education and curricula with broader cultural processes" (Lopes and De Macedo 2003, 201).

In South Africa, there is recognition that, for example, the debate on decolonisation of the curriculum has propelled universities to review curricula, teaching and learning approaches and to interrogate the assumptions that underpin the prioritisation of Eurocentric knowledge systems. Two approaches appear to have been offered to academics: "In your own discipline, you may first want to adopt a content-driven additive approach and expand the curriculum already in place. Or you may want to adopt the different approach of considering how the object of study itself is constituted, what tools are used to study it, and what concepts are used to frame it" (Garuba 2015). The reality is that South African universities are modelled on traditional, often British, university structures. Secondly, the legacy of apartheid continues to loom over us. In this relatively unchanged context, it is clear that while our curricula may have satisfied the utilitarian requirements of transformation, not much has been effected to systemically address the transformation envisaged 22 years ago. Access and equity, responsiveness, and efficiency and effectiveness are competing tensions reflecting also competing priorities. It is not clear that the competing demands on HE in South Africa have permitted for any significant impact at the level of policy and strategy, whether we are talking of individual institutional level, or at a national level. Institutional curriculum management appears to be at risk of being fossilised by the activities of the quality "guard dogs", focused as they are on compliance. Against this backdrop, and ironically for some, it is perhaps as easy as it ever was to preserve the ivory tower of curriculum transformation. In the performativity-driven environment in which we operate, the focus on quantitative outputs rather than on the fundamental interrogation of the hidden spaces of the curriculum, keeps those places securely out of reach of both policy and change.

\section{NOTE}

1. NATED Reports 150 and 151.

\section{REFERENCES}

Allais, Stephanie M. 2003. The National Qualifications Framework in South Africa: A democratic project trapped in a neo-liberal paradigm? Paper presented at a conference on 14 March 2003, UKZN. http://ccs.ukzn.ac.za/files/allais.pdf

Arnolds, Cecil A., Regina N. Stofile, and Riyaadh Lillah. 2013. Assessing the outcomes of the higher 
education mergers in South Africa: Implications for strategic management. Acta Commercii 13(1), Art. \#175.

Badat, Salim. 2010. The challenges of transformation in higher education and training institutions in South Africa. Johannesburg: Development Bank of Southern Africa.

Barnett, Ronald, Gareth Parry and Kelly Coate. 2001. Conceptualising curriculum change. Teaching in Higher Education 6(4): 435-449. https://doi.org/10.1080/13562510120078009

Biggs, John. 2014. Constructive alignment in university teaching. HERDSA Review of Higher Education 1(1): 5-22.

Cameron, William B. 1963. Informal sociology: A casual introduction to sociological thinking. New York: Random House.

CHE see Council on Higher Education.

Council on Higher Education. 2013. Framework for Qualification Standards in Higher Education. CHE: Pretoria. http://www.che.ac.za/media_and_publications/frameworks-criteria/seconddraftframework-qualification-standards-higher

Council on Higher Education. 2004. Criteria for programme accreditation. http://www.che.ac.za/sites/ default/files/publications/CHE_accreditation_criteria_Nov2004_0.pdf

Council on Higher Education. 1998. Mandate. http://www.che.ac.za/about/overview_and_mandate/ mandate

Cross, Michael. 2004. Institutionalising campus diversity in South African higher education: Review of diversity scholarship and diversity education. Higher Education 47(4): 387-410.

Crowe, Tim. 2016. Science and decolonisation: A way backward. https://www.news.uct.ac.za/images/ archive/dailynews/downloads/2016/2016-23-11_science-and-decolonisation-way-forward.pdf

Department of Education. 2001. National Plan for Higher Education. Department of Education. DoE: Pretoria. http://www.dhet.gov.za/Gazette/Gazette\%20no\%2037928,Notice\%20681\%20of\%20 2014,Department\%20of\%20Higher\%20Education\%20and\%20Training.pdf

Department of Education. 1997a. White Paper 3: A Programme for the Transformation of Higher Education. DOE: Pretoria. http://www.education.gov.za/DocumentsLibrary/Legislation/ WhitePapers/tabid/191/Default.aspx

Department of Education. 1997b. Higher Education Act No. 101 of 1997. Department of Education: Pretoria. http://www.acts.co.za/higher-education-act-1997/index.html

DoE see Department of Education.

Foucault, Michel. 1988. Madness and civilization: A history of insanity in the age of reason. New York: Vintage Books.

Garuba, Harry. 2015. What is an African curriculum? Mail \& Guardian, 17 April. http://mg.co.za/ article/2015-04-17-what-is-an-africancurriculum/

Jansen, J. D. 1998. But our natives are different! Race, knowledge and power in the academy. Social Dynamics 24(2): 106-116.

Kamanzi, Brian. 2016. Decolonising the curriculum: The silent war for tomorrow. Daily Maverick, 18 October. http://www.dailymaverick.co.za/opinionista/2016-04-28-Decolonising-The-Curriculum -The-Silent-War-For-Tomorrow/\#.Wax2pov96cm

Kamola, Isaac A. 2011. Pursuing excellence in a "world-class African university": The Mamdani Affair and the Politics of Global Higher Education. Journal of Higher Education in Africa 1/2: 147-168.

Le Grange, Lesley. 2016. Decolonising the university curriculum. South African Journal of Higher Education 30(2): 1-12.

Le Grange, Lesley. 2009. The university in a contemporary era: Reflections on epistemological shifts. In Higher Education in South Africa: A Scholarly Look behind the Scenes, ed. E. Bitzer, 103-119. Stellenbosch: Sun Media.

Lopes, Alice C. and Elizabeth F. de Macedo. 2003. The Curriculum field in Brazil in the 1990s. Erlbaum 
Associates, Inc: New Jersey.

Lyotard, Jean-Francois. 1993. The postmodern condition: A report on knowledge. Translation from the French by Geoff Bennington and Brian Massumi. Minneapolis: University of Minnesota Press.

Mbembe, Achille. 2015. Decolonizing knowledge and the question of the archive. Public lecture, Johannesburg, Wits Institute for Social and Economic Research (WISER). https://wiser.wits. ac.za/system/files/Achille\%20Mbembe \%20-\%20Decolonizing\%20Knowledge\%20and $\% 20$ the $\%$ 20Question $\% 20$ of $\% 20$ the $\%$.pdf

Ndlovu-Gatsheni, Sabelo J. 2013. Why decoloniality in the 21st Century? The Thinker 48: 10-15. http://www.thethinker.co.za/resources/48\%20Thinker\%20full\%20mag.pdf

Osborne, David and Ted Gaebler. 1992. Reinventing government. New York: Addison-Wesley.

Pandey, Sid N. and Fazlur R. Moorad. 2003. The decolonization of curriculum in Botswana. New Jersey: Lawrence Erlbaum Associates, Inc.

Pinar, William F. 2004. What is curriculum theory? Mahwah, NJ: Erlbaum.

Ramrathan, Labby. 2016. Beyond counting the numbers: Shifting higher education transformation into curriculum spaces. Transformation in Higher Education 1(1): 1-8.

Republic of South Africa. 2015. The 2015 Durban Statement on Transformation in Higher Education, 17 October 2015. http://www.dhet.gov.za/summit/Docs/2015Docs/2015\%20Durban\%20HE\% 20Transformation\%20Summit\%20Statement.pdf

Republic of South Africa. 2008. Report of the Ministerial Committee on Transformation and Social Cohesion and the Elimination of Discrimination in Public Higher Education Institutions, Chapter 6, 30 November. Pretoria: Government Printer.

RSA see Republic of South Africa.

Shay, Suellen. 2016. Decolonising the curriculum: It's time for a strategy. The Conversation, 13 June. https://theconversation.com/decolonisingthe-curriculum-its-time-for-a-strategy-60598

Spracklen, Karl. 2011. Playing with madness in the forest of shadows: Dissonance, deviance and nonconformity in the black metal scene. Can I Play with Madness? (2011): 169.

Stone, Lynda. 1994. Modern to postmodern: Social construction, dissonance, and education. Studies in Philosophy and Education 13(1): 49-63.

Waghid, Y. and N. Davids. 2017. Towards a university of critique. In Thinking university: A philosophical examination of thought and higher education, ed. R. Barnett and S. Bengsten, 6176. Switzerland: Springer. 